\title{
Use of a Digital Storytelling Workshop to Foster Development of Intergenerational Relationships and Preserve Culture with the Nak'azdli First Nation: Findings from the Nak'azdli Lha'hutit'en Project
}

\author{
Shannon Freeman, ${ }^{1}$ Jenny Martin, ${ }^{2}$ Carrie Nash, ${ }^{3}$ Simone Hausknecht, ${ }^{4}$ and Kelly Skinner ${ }^{5}$
}

\begin{abstract}
RÉSUMÉ
La communauté autochtone Nak'azdli Whut'en du nord de la Colombie-Britannique a reconnu l'importance de préserver et de partager entre les générations la sagesse, les connaissances culturelles et les traditions orales des aînés. Nous présentons les résultats d'un atelier intergénérationnel portant sur les récits numériques, dirigé par le Nak'azdli Health Centre, en collaboration avec des organismes communautaires et des partenaires universitaires. Dans le cadre d'un plan d'action participatif conçu conformément aux principes PCAP®, un atelier de 10 séances a été créé et mis à l'essai. La technologie WeVideo a été utilisée pour faciliter le partage des connaissances entre des élèves du primaire et des aînés. Les aînés ont partagé leur expérience et leurs connaissances à travers leurs récits. Les élèves ont enregistré les récits des aînés et y ont ajouté des images et des sons pour transposer la vision des aînés sous une forme numérique. Ainsi, les aînés et les élèves ont œuvré en partenariat pour co-créer des récits numériques constituant un héritage culturel pour les générations futures. Cet atelier était en accord avec le programme scolaire de la Colombie-Britannique. Il a favorisé les relations intergénérationnelles entre les aînés et les jeunes, a contribué à la préservation de l'identité culturelle et à la valorisation du rôle des aînés et des jeunes dans leur communauté.
\end{abstract}

\begin{abstract}
The Nak'azdli Whut'en, a First Nations community in northern British Columbia, recognized the importance of preserving Elders' wisdom and sharing cultural knowledge and oral traditions across generations. We report learnings from an intergenerational digital storytelling workshop led by the Nak'azdli Health Centre in partnership with community organizations and academic partners. Framed by a participatory action design in accordance with the Ownership, Control, Access, and Possession $\left(\mathrm{OCAP}^{\circledR}\right)$ principles, a 10 session workshop was created and piloted. WeVideo technology was used to facilitate knowledge sharing between elementary school students and Elders. Through storytelling, the Elders shared their wisdom and knowledge. The students recorded the stories and added imagery and sounds to capture their understandings in a digital format. Thus, Elders and students worked in partnership to co-create digital stories to create a cultural legacy for future generations. This workshop aligned with the British Columbia school curriculum, fostered intergenerational relationships between Elders and youth, helped preserve cultural identity, and facilitated opportunity for meaningful contribution for Elders and youth to their community.
\end{abstract}

\section{DAKELH ABSTRACT}

Nak'azdli Whut'enne, no BC 'et Dakelh huwhut'i. Whunihne ne'hut'en-un 'et whuhudilhti' ts'iyanne huba. Nak'azdli Health Centre 'ink'ez keyoh lhulh 'uhut'enne 'ink'ez hodul'ehne 'ilhunahosdil, 'ink'ez nawhuhulnuk'en 'uk'une'huzguz. Whunizyatdun 'ilhunahosdil 'ink'ez lha'hut'en whe lhahuduja. OCAP bu k'un'a. Ts'oodune hodul'ehne 'ink'ez whunihne 'andit k'un'a 'uk'une'huzguz WeVideo 'i be lhulyahulduk. 'Et whuz un'a whunihne nawhuhulnuk. Hodul'ehne buk'une'huzguz buk'un'a hinilh'en. Whunihne 'ink'ez hodul'ehne nus de dizulhne buba' huyinla. Ndi 'ut'en 'i BC ndet huhodul'eh-un huba' huyinla 'et soo whunihne 'ink'ez hodul'ehne lhulh 'uhoot'en huba.

1 School of Nursing, University of Northern British Columbia, Prince George, British Columbia.

2 Council Member, Nak'azdli Whut'en, , British Columbia.

3 Nak'azdli Health Centre, Fort St. James, British Columbia.

4 Faculty of Education, Simon Fraser University, Burnaby, British Columbia.

5 School of Public Health and Health Systems, Faculty of Applied Health Sciences, University of Waterloo, Waterloo Ontario

Canadian Journal on Aging / La Revue canadienne du vieillissement 39 (2) : 284-293 (2020) 
* Snachailya! We thank the Nak'azdli Whut'en for their support and efforts to make this workshop a reality. We also thank all the Elders who participated, especially Elder Lillian Sam for her leadership, staff of the Nak'azdli Health Centre, Nak'azdli community members, and Nak'al Bun students and educators who were all actively engaged in the Nak'azdli Lha'hutit'en project. We are very appreciative of the time, wisdom, and insight provided by Nellie Prince, Yvonne Pierreroy, and Lillian Sam for their translation of the abstract. This work was funded by a grant from the AGE-WELL Strategic Investment Program (AWSIP-A16-013).

Manuscript received: / manuscrit reçu : 25/07/18

Manuscript accepted: / manuscrit accepté : 03/02/19

Mots-clés : vieillissement, population autochtone, âgé, adolescent, récit numérique, savoirs autochtones, recherche participative communautaire

Keywords: aging, Indigenous population, aged, adolescent, digital story, Indigenous knowledge, community based participatory research

La correspondance et les demandes de tirés-à-part doivent être adressées à : / Correspondence and requests for offprints should be sent to:

Shannon Freeman, Ph.D.

School of Nursing

University of Northern British Columbia

3333 University Way

Prince George, British Columbia

Canada V2N 4 Z9

(Shannon.freeman@unbc.ca)

\section{Introduction}

The Nak'azdli Whut'en is a non-treaty First Nation whose traditional territory extends across the central interior of British Columbia (BC) Canada (Nak'azdli Whut'en, n.d.). The population of the Nak'azdli Whut'en is approximately 2,000 members with approximately one third living on their 18 reserves (Northern Health, Nak'azdli Whut'en, \& Tl'azt'en First Nation, 2015). Many Nak'azdli members live off reserve in the neighbouring town of Fort St. James and the city of Prince George, BC. Other members live farther away in urban areas including Vancouver and beyond (Northern Health, Nak'azdli Whut'en, \& Tl'azt'en First Nation, 2015). The Nak'azdli Whut'en, part of the Carrier Nation, value their sense of community and their ways of working together. Their Dakelh culture and way of life are closely tied to the land and highly value the possession of knowledge as a community.

Since 2001, the proportion of older adults (over 65 years of age) has grown steadily and more than doubled within the First Nations population in Canada (O'Donnell, Wendt, \& the National Association of Friendship Centres, 2017). However, across the life course, older First Nations adults have faced substantial challenges including loss of cultural and traditional heritage and trauma experienced from a history of residential schools in Canada (Bombay, Matheson, \& Anisman, 2009). For the Nak'azdli Whut'en, much of the Dakelh culture, language, and heritage of the Nak'azdli Whut'en was damaged and lost during the history of colonialism in Canada and especially during the time of residential schools. This has led to gaps and loss of knowledge, including knowledge of traditional medicines (i.e., harvesting and preparation of medicines, locations of medicinal plants, and ceremonies), language, history, and their governance system (Northern Health, Nak'azdli Whut'en, \& Tl'azt'en First Nation, 2015). Faced with these and other impacts on their families, the loss of intergenerational transfer of culture has been felt throughout their community. In response, the Nak'azdli Whut'en have become actively engaged in the development of community-driven innovative approaches designed to promote the quality of life and well-being of their people.

To preserve their history, language, and culture, the Nak'azdli Whut'en have prioritized the need to foster a sense of community among their members. Within the Nak'azdli community, there are Elders who are recognized and highly respected as keepers of the Dakelh knowledge and oral histories. The term "Elder" refers to those members who are recognized by the Nak'azdli people to hold knowledge of their people. This knowledge can vary greatly and often includes cultural or historical knowledge (e.g., traditional medicines, Bahlats [potlach], clan systems, and creation stories). Although there is no age requirement in the Nak'azdli community for someone to be considered an Elder, most Elders are over 50 years of age, and the majority are over 60 years of age.

Elders often share their knowledge with younger generations through the oral tradition of storytelling. Throughout human history, storytelling has been used to communicate and share information, to entertain, and to educate others. Textbooks, religious books, movies, and more are used as means to preserve pieces 
of history, experiences, and knowledge for others to disseminate information. Storytelling has played an important role in preserving history in non-Indigenous and Indigenous cultures (Archibald, 2008; Christensen, 2012; Cunsolo Willox, Harper, Edge, "My Word": Storytelling and Digital Media Lab, \& Rigolet Inuit Community Government, 2013; Fletcher \& Mullett, 2016), but these histories are not so easily saved. Little is written of the Dakelh history and culture. Instead, the knowledge of the Dakelh people is shared through the oral tradition of storytelling. Nak'azdli children are taught to listen quietly to Elders sharing stories describing "events, people, supernatural events, moral stories, and stories that explain how the world came to be" (Northern Health, Nak'azdli Whut'en, \& Tl'azt'en First Nation, 2015).

In our earlier work, we have written about the findings of the Nak'azdli Elder survey that was led by the Nak'azdli Health Centre and Nak'azdli Elders in the spring of 2016 (Tonkin, Freeman, Martin, Ward, \& Skinner, 2018). This survey asked Elders which activities they found meaningful and were interested in engaging in, should the activity be provided in the Nak'azdli community. Findings from the survey highlighted that the Elders' most highly valued opportunity was to engage as givers of knowledge in their community through wisdom-sharing activities and programs with others, especially young people. Nearly all Elders (97.4\%) identified enthusiasm for intergenerational and family centred wisdom-sharing activities, including sharing cultural skills with young generations, traditional storytelling, language learning, cultural camps with younger generations, and harvesting and preserving activities (i.e., berry picking, fishing, hide tanning, preserving food) (Tonkin et al., 2018). Aligning with the Nak'azdli Whut'en view of their community as "a holistic community that believes in maintaining and enhancing traditional values by learning, living and teaching their culture and language" (Nak'azdli Whut'en, n.d.), more than half of the Elders surveyed desired to share skills, stories, and knowledge.

Following completion of the Nak'azdli Elder survey (Tonkin et al., 2018), a team of Nak'azdli community representatives led by the Nak'azdli Health Director, came together with a team of University researchers to co-create an intergenerational program designed to engage Elders in meaningful ways. The program aimed at engaging Elders with youth in the community to capture and share the Elders' wisdom and knowledge with present and future generations. Digital storytelling was selected as the focus of the program, as it has been shown to be an effective tool to support health promotion and enhance intergenerational knowledge exchange in communities where history is commonly shared in an oral fashion
(Cueva, Kuhnley, Revels, Schoenberg, \& Dignan, 2015; Fletcher \& Mullett, 2016). Given the Elders' interests in storytelling and recognizing that youth in the Nak'azdli community are very engaged with modern technology, the team selected digital storytelling as the medium to bring both youth and Elders together to work in a meaningful way.

Digital storytelling, the process of creating and telling a story by combining audio-recording, images (both still and video), and music and sound, has been used as a tool to preserve Indigenous culture and tell oral histories (Burgess, 2006; Christensen, 2012; Fletcher \& Mullett, 2016; Klaebe, Foth, Burgess, \& Bilandzic, 2007; Lambert, 2006). For older adults in particular, digital storytelling has been found to be a form of legacy, an opportunity to reflect on life, and helps promote social interactions across space and time (Hausknecht, VachuOrosco, \& Kaufman, 2018). The goal of this project was to use digital storytelling to promote intergenerational relationships between Nak'azdli youth and Elders through the sharing of their stories and supporting the students in learning more about the Dakelh culture and history. At the same time, the digital stories created would help to preserve the stories held by the Elders for future generations.

\section{Approach, Participants, and Process}

Approach

This project was given the name "The Lha'hutit'en Project" by a leading Elder in the Nak'azdli community. In the Dakelh language, "Lha'hutit'en" means "we work together, we help one another". This title embodies the community-based participatory action approach that was used in which the community and academics worked together collectively for the benefit of one another. Throughout the process, a central theme guiding the participatory action approach was shared learning. Shared learning combined with authentic partnership among team members allowed a deconstruction of power dynamics among all partners involved. This set the stage for Indigenous community partners and participants to engage in research with academics in a beneficial and respectful manner (Cunsolo Willox et al., 2013). This mutually beneficial reciprocal relationship was fostered in a spirit of co-creation of project activities, and supported the occurrence of flexibility and adjustments during the process.

A number of Nak'azdli community members were engaged throughout the Lha'hutit'en project. The advisory committee, led by the director of the Nak'azdli Health Centre, was composed of community partners, including representatives from the Nak'azdli Health Centre, the Nak'azdli Elder Society, the Nak'al Bun 
Elementary School, and the Nak'azdli Whut'en Youth Council, as well as a Nak'azdli First Nations community development consultant. Academic partners included researchers and students from three Canadian universities.

Employing a community-based participatory approach supported co-learning and capacity building among and between community members and research team partners. Participatory research methods were ideal for this digital storytelling workshop "in ways that make sense, that speak to and speak with" (Christensen, 2012) members of the Nak'azdli community. Through this approach, the Nak'azdli community was recognized as the unit of identity, and all aspects of this project aimed to build on the community strengths and resources in $\mathrm{Nak}^{\prime}$ azdli, including the active involvement of the community in the activities of the Nak'al Bun Elementary School. Nak'al Bun is an independent school operated by the Nak'azdli Whut'en and offers specialized activities and historical components (e.g., heritage week, ice fishing, net setting, beading, and traditional medicines) to teach the students the Dakelh (Carrier) language and culture (Nak'azdli Whut'en, n.d.). Nak'al Bun envisions that all students "can succeed and become positive contributors to our [the Nak'azdli] community" and aims to promote academic and personal learnings as well as to instill the importance of social and cultural development among the students (Nak'al Bun Elementary School, n.d.).

\section{Participant Selection}

In January 2017, a planning meeting was held involving community partners and the teachers of Nak'al Bun. Upper year elementary school students were selected as a focal group because of scheduling availability and enthusiasm and the leadership of homeroom teachers. A list of Elder participants to be invited to participate in the digital storytelling workshop, was developed. In drafting the list of invitations, community members identified Elders recognized as community wisdom holders or engaging storytellers, or who were kin to the current students, and who would be available during the scheduled workshop times. A wide range of Elders was sought including those from surrounding communities. Informed written consent to participate was obtained from all Elders and parents of students. Oral assent to participate was gathered from students by the teachers.

\section{Process}

A six step process was adapted by team members from a process previously used in digital storytelling workshops held with older adults developed by Hausknecht, Vanchu-Orosco, and Kaufman $(2016,2017)$ and is shown in the top row of Figure 1 (Hausknecht, 2018). The Nak'azdli intergenerational workshop was designed to be held in 10 afternoon sessions of 2.5 hours each. To meet scheduling constraints identified by the school, 10 dates were selected over a 4 week period in the spring of 2017 to offer the workshop. Students were put into mixed-grade groups of three to four students and paired with one or two Elders. Some Elders brought caregivers or other family members with them for translation and support purposes.

WeVideo, a video editor software program available online, was selected because it was browser based and could be accessed from home, school, or elsewhere (https://www.wevideo.com/). It also was accessible by both PC and Mac computers. This was important as it was hoped that students would also work on the project at home, and possibly use the program for future creative works, both for school or personal reasons.

The first three workshop sessions involved all Elders and students and focused on introducing the idea of digital storytelling, getting to know each other, and the sharing of stories in large and small groups. During the first workshop session, everyone gathered in a circle and passed a feather (used as a talking object) so that all Elders, students, teachers, and researchers had an opportunity to introduce themselves and share where they are from and who their parents and grandparents are. This practice of introducing oneself by noting where one is from and describing one's immediate family background is used by the Nak'azdli Whut'en as a way of establishing who each person is in the community and how that person is related to other community members. Many Elders in the room were familiar with students' parents, grandparents, and even greatgrandparents, and this helped to make an immediate connection and build trust and rapport. During the sessions when Elders came, Labrador tea and bannock were served to them by the students and were shared amongst the group.

Session four was specific to the students, during which they began storyboarding and working with WeVideo technology, and was not attended by the Elders. Sessions 5 through 10 focused on creating the digital story. For these sessions, topics focused on: (1) audio recording stories and sound; (2) photos, videos, and visual effects; (3) layering sound and music; (4) editing, titles, and credits; and (5) video publishing and sharing. Elder participation in sessions six and seven were optional and not all Elders attended. In response to changes in the availability of the students, the final four sessions (6 through 10) were collapsed from five into four sessions. An additional drop-in session was offered on a group-by-group basis to work directly with a research assistant in troubleshooting 
Original Version: Wisdom Stories - Workshop with Older Adults (Hausknecht, 2018)

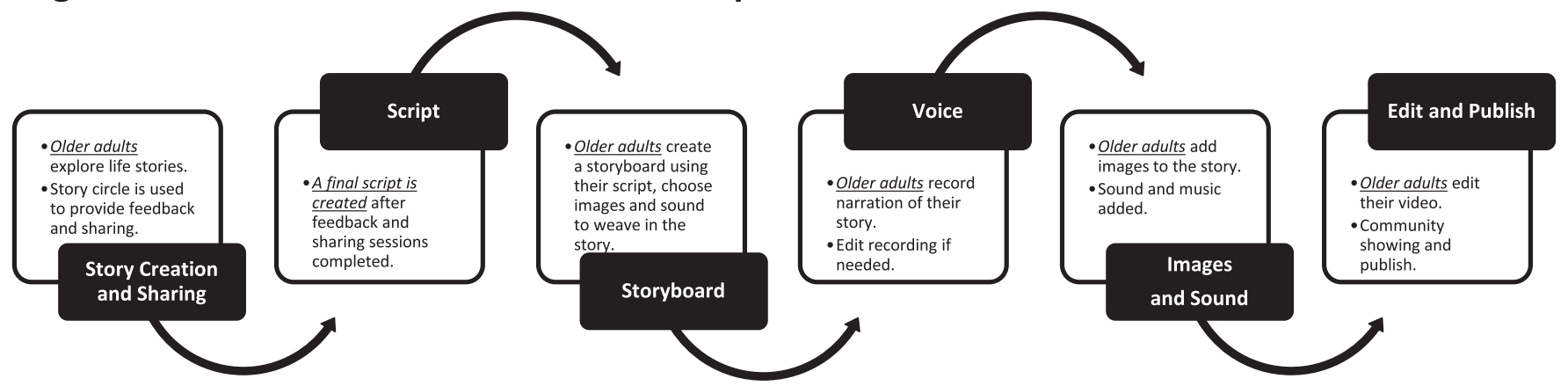

\section{Adapted Version: Intergenerational Digital Storytelling with Nak'azdli Elders and Youth - Lha'hutit'en Workshop Plan}

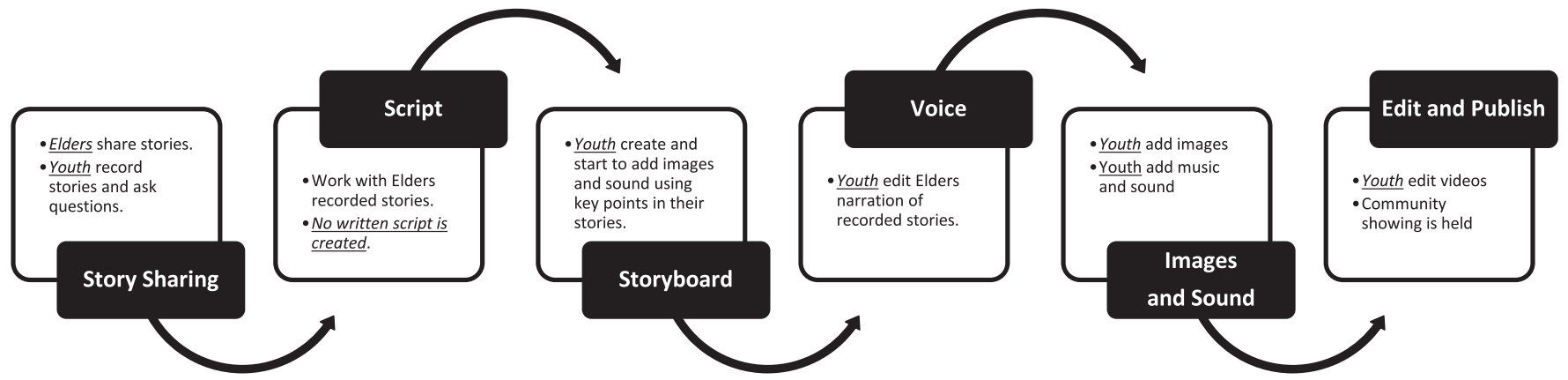

Figure 1: Original Wisdom Story Workshop plan (top row) based on Workshops with Older Adults (Hausknecht, 2018) and Adapted Digital Storytelling Workshop plan (bottom row) for the Lha'hutit'en Project

any outstanding issues prior to publishing of the videos. After the workshop sessions concluded, a community showcase event and feast was held at the Nak'azdli Whut'en Kwah Hall.

Semi-structured focus groups were conducted with students in their classrooms at midway and at the end of the project, whereas individual semi-structured interviews were held with Elders and teachers at the end of the project. Participants were asked to share their experience in the workshop and their impressions of digital storytelling before, during, and following the 10 session workshop. Focus group and interview data were transcribed and analysed using qualitative descriptive and thematic analysis. A community showcase event with the Elders, students, and educators from Nak'al Bun Elementary School was held at the end of the project, and community attendees voluntarily completed surveys. A copy of this survey is available upon request from the primary author. Summarized data from the surveys are provided. Qualitative descriptive analysis followed the six analytic strategies as described by Miles and Huberman (1994). Data were coded from field notes from research team members and from focus group and interview data collected from teachers, students, and Elders. To remain authentic and representative of workshop participants, qualitative descriptive analysis allowed us to remain closer to the data and more specifically to the words shared by participants (Neergaard, Olesen, Andersen \& Sondergaard, 2009).

Harmonized ethics review was received from the (University of Northern British Columbia and Simon Fraser University E2016.1020.083.01H). The Ownership, Control, Access, and Possession $\left(\mathrm{OCAP}^{\circledR}\right)$ principles (First Nations Information Governance Centre, 2014) governed all aspects of this research study and as such, all digital videos created remain the property of the Elders and students and the Nak'azdli community.

\section{Findings}

Ten groups of Nak'al Bun senior elementary students $(n=31)$ and Elders from the Nak'azdli and surrounding First Nations communities $(n=13)$ participated in the digital storytelling workshop sessions. Each group successfully produced a 4-7 minute digital story, which was showcased at a community event attended by over 75 community members. Survey responses were provided by 72 community members. The digital stories covered a wide range of topics including legends (e.g., The Story of the Loon, The Mosquito Man), traditional 
medicines (e.g., The Tree Story, Herbal Medicine), and personal stories (e.g., The Best Hockey Story, Why I Became a Poet, Hunting Stories) of the Elders. Benefits from the workshops reported by Elders $(n=13)$, students $(n=31)$, members of the wider community $(n=72)$, and educators $(n=4)$ are discussed further. The feedback received via the midway point focus groups with students and Elders; the concluding focus groups and interviews with teachers, students, and Elders; and survey responses from community members reflects the positive impacts of participating in the digital storytelling project. Not only were connections made between the Nak'azdli elementary students and the Elders, but also relationships between the Elders themselves were strengthened and their deep purpose as teachers and knowledge keepers in the community was acknowledged. This public acknowledgement and the weekly engagement with students were noted by community members to have had a positive impact on the Elders' mental health and well-being. Community attendees found each of the 10 digital stories (listed as A to J in Figure 2) to be enjoyable (range 91.1-100\%) and interesting (range 86.7-100\%).

Elders shared with the students the protocol for, and importance of, acknowledging where the legend comes from when it is being passed down to them. Among the Nak'azdli Whut'en, only certain stories can be told by certain clans according to protocol. The students were particularly interested in legends about animals: "I like digital storytelling because you get to learn about how things like how the loon got white on it and things like that."

The students took great pride in their abilities to create a digital story and to learn how to use the WeVideo technology. Students embraced, and mastered the WeVideo technology quickly. Students enjoyed using laptops and iPads and were keen to do the hands-on

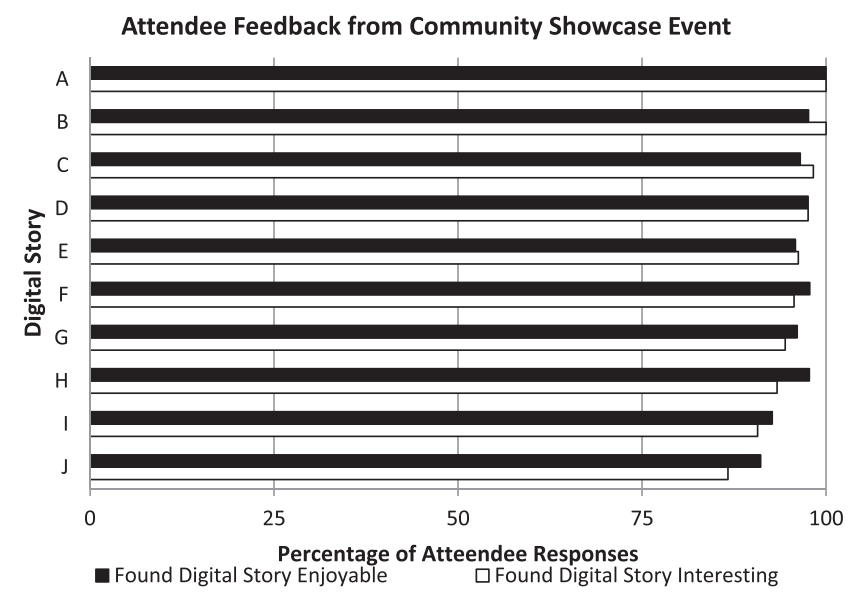

Figure 2: Feedback from Lha'hutit'en Project Community Showcase Event attendees $(n=72)$ activities, such as adding in music, photographs, and sound. Many students found the workshop enjoyable. Participants noted: "I enjoyed talking and asking the Elders questions. It was fun. I liked the editing. I liked talking to the Elders. You could learn things."

When asked how they felt the community would respond when seeing their digital videos at the community event, one student responded: "I think they [the community] will be surprised because we are young and it's a new thing and the first time they will see things like this in the community."

Another student noted: "I think they [my parents] will think we did a good job. They will like it. They will be proud."

The Elders emphasized their enjoyment in meeting and building relationships with the students and with one another. One Elder noted: "I loved the kids. They were really attentive. And I felt good."

Another noted: "My grandchildren were happy to see me there. I don't get to see them often at home. So, I see them at school and they were surprised. It brings our relationship closer. I think more parents and leaders should visit the school."

Elders also reported that they enjoyed talking to other Elders and hearing each other's stories. In some cases, Elders shared different stories on similar topics highlighting the diversity of their oral history. Elders emphasized the benefits that the sharing of their stories has a legacy for future generations. They felt that the students were enthusiastic to listen to them and learn about their culture and heritage. One elder noted that: "They [the schoolchildren] were really interested. That is what I liked. I told them about my regalia and the potlatch."

Another Elder noted that: "The children wanted to learn more about the sweat lodge and ceremonies and healing too."

Elders also highlighted the importance that the workshop had to preserve their language. "It's really important to talk Carrier to our children. It's a start. A lot of clans - they don't know the full language correctly."

Elders saw the digital storytelling workshop as an opportunity not only to teach stories but also to teach culture, history, and language.

The educators, including teachers and the principal of Nak'al Bun School saw great opportunities to preserve culture and promote language among the students of the workshop. One educator noted that: "Having Elders come in and work closely with kids. The connection [was meaningful]. We often have pressure to bring Carrier into our classroom. And that is very difficult to do.... This was a very creative way to do it." 
Attention was paid to aligning the digital storytelling workshop with the BC curriculum and learning standards. The educators were very enthusiastic about this new innovative way to address curriculum expectations. One educator noted: "The whole idea is great. It does touch on a lot of the curriculum."

Another educator noted:

It was really nice to have that portion of the curriculum to have ideas for this part of the curriculum. I would never have brought technology in the classroom that way. Usually people ask about technology in the classroom and we are like "I have a smart board...". But what do your kids really do with the technology? That is the question.

As the new BC curriculum has an emphasis on Indigenous knowledge, community engagement, and technology integration, this project met many of the core competencies (Province of British Columbia, 2018). Furthermore, it addressed some specific curriculum competencies in both the language arts and applied design, skills, and technologies. For example, the digital storytelling process meets the standards for one of the modules in applied design, skills, and technologies for media arts for grades 6 and 7 :

- Media Arts module (BC Curriculum)

- Students will be able to distinguish characteristics and uses of digital and non-digital media

- Techniques for using images, sounds, and text to communicate information, settings, ideas, and story structure

- Media technologies and techniques to capture, edit, and manipulate images, sounds, and text for specific purposes; and

- Influences of digital media for the purpose of communication and self-expression (Province of British Columbia, 2018).

After the workshop and the community event were completed, students continued to use the WeVideo technology. One teacher enthusiastically reported how students were asking to use the iPads to create digital stories of their own during recess and lunch breaks.

The kids are making their own stories right now. It's really funny. Have you ever watched My Strange Addiction on TLC? They were like our grade six strange addiction was the dab. Our grade seven strange addiction is slime. They all bring slime to school. They went around the school interviewing people. They have it on the iPad. Today they stayed in for lunch by choice to make a WeVideo on the iPad. It is so cool. They do like the process.

Community members responded positively to the digital stories showcased at a community event. Community members shared their enjoyment of watching the Elders working with youth in the community to pass on traditions, and recognized the value that the sharing of stories has to youth and Elders. One attendee wrote, "It's a wonderful way to have the kids and Elders do things together. Healthy for all of them. Should do this every year. They will never be 'out of stories'." Attendees noted that watching the digital stories evoked feelings of happiness, respect, admiration, pride, and awe. Attendees were proud of the children who were able to use technology to create the stories and they felt joy because the stories were so detailed. One attendee noted emotion in "listening to the heart in the stories and how proud the Elders were to share".

Community showcase attendees also noted that the hearing of stories brought back memories of others who used to tell these stories when they were young and the importance of continuing to share the stories forward. One attendee wrote, "I brought my babies so I enjoyed that my children got to hear the stories." Attendees highlighted the importance of passing these stories on to their children. "Every person has a story to tell and that is how we learn then teach other people."

\section{Discussion}

This digital storytelling workshop illustrates the benefits of using technology as a bridge across the generations, supporting opportunity for mutual sharing and learning by Elders and youth. Everyone connected with the project reported positive benefits at personal (i.e., feelings of satisfaction and success) and community (i.e., relationship building and cultural preservation) levels. The digital stories captured cultural, mythological, and personal stories now held by the Elders for the Nak'azdli community to share in a digital format. Digital storytelling has been known to provide a platform that can support a sense of connection (Cunsolo Willox et al., 2013; Fletcher \& Mullett, 2016; Hausknecht et al., 2018). Cunsolo Willox and colleagues (2013) note that this platform supports "people to not only to remember their roots, but also to connect to themselves, their histories, their ancestors, and their culture through stories and video". Findings from a student participant in this study support this notion: "I think it's fun because I get to hear about my Grandmother, and I get to know a bit more about how her family was a long time ago and how she used to do things a long time ago."

The Elders' stories revealed to students how different their lives are by comparison to how their Elders lived at their age. Elders shared many stories about life when they were young. One Elder shared several stories about hunting moose for the first time when he was 13 . In sharing this story, a student made a connection to a particular piece of land that the Elder was speaking about, as her grandmother has her trap line nearby. They made a connection between their families and 
the land they have both traveled, up certain streams and rivers and trap lines. The students and Elders talked about catching rabbits with a snare and making "Indian ice cream" out of dried blackberries and bear grease. When viewing the digital stories at the community showcase event, attendees also recognized the value of learning the unique personal experiences of the Elders and how they had a large impact on the Elders' life stories.

The students were encouraged to ask questions of the Elders and inquire about stories that they were interested in learning more about. Christensen (2012), reported similar findings in which both Elders and youth were made aware of the meanings that each associated with physical geography and place through the sharing of stories and the process of co-creating the digital story. This shared connection and questioning challenged students to alter their knowledge and understanding of the past, and encouraged Elders to share more.

The original digital storytelling workshop used by Hausknecht et al. (2018) required adaptation to meet the needs of the Elders and students. Like Lafontaine and Sawchuk (2018), we too "recognized that working with different groups and in different settings can drastically change learning contexts" (p. 492). Sawchuk (2016) extended this, noting that use of technology may be affected by a wide range of factors including: "cultural context, the gender of subjects, their socioeconomic circumstances, personal histories of engagement with ICTs [Information and Communication Technologies], general literacy and education and the kinds of infrastructures that are in place in a region" (p. 9). For the current study, this meant being aware not only of the cultural context experienced by members of the Nak'azdli community, but also of the learning dynamics of the Elders and youth. This led to the removal of the script-writing component and an emphasis on using digital recording devices to capture the stories as shared orally by the Elder. In this way, the workshop remained inclusive of all participants regardless of literacy level or language. Some Elders exclusively spoke the Dakelh language, whereas for some students, reading and writing could be challenging. Therefore, employing an arts-based approach to the digital storytelling workshop supported there being an opportunity for all to engage. In one case, this enabled a student, who was typically disengaged in learning activities, to take on a leadership role in the search for music, video, and pictures to evoke the feelings and meanings of the Elder's story. In another context, an Elder who only spoke the Dakelh language was still able to share stories with the support of an accompanying family member who could translate. In this case, a digital story in the Dakelh and English languages was created. Another Elder who was very hard of hearing was able to communicate with students who were able to write their questions using a large marker on a white board. The group nature and team approach to co-learning throughout the digital storytelling workshop supported students and Elders to express their emotions, creatively brainstorm, and problem solve together as a team.

The digital storytelling project was an opportunity for Elders to share traditional stories and to pass on teachings about the way knowledge is handled and where it comes from. Several Elders shared teachings through their stories, such as how traditional medicine is harvested and prepared or how traditional foods such as beaver and martin are trapped and prepared. Both Elders and youth recognized the social value of sharing this knowledge between generations and of the acknowledgement and witnessing of the Elders as keepers of sacred teachings. At the same time, students were enthusiastic about using computers and iPads and embracing new software, and they quickly learned how to use the WeVideo software. As previously reported by Livingstone and Bovill (2013) and Ouellet, Romero, and Sawchuk (2017), the students mastered the new software through trial and error, by experimenting with software functions, and by exploring through doing. The quick mastery of the technology and group dynamics of the oral story sharing allowed co-learning to occur between the Elders and students. From an intergenerational perspective, both groups were engaged as both givers and receivers of new knowledge: the Elders shared their oral culture and stories while the students shared their mastery of the WeVideo technology. Like the students, the Elders were also inquisitive and curious about learning to use the WeVideo software technology, but instead of learning through tinkering, the Elders learned from the students.

Residential schools and childhood trauma are common experiences for many First Nations Elders in Canada. However, for the purpose of the current pilot workshop, it was decided by the advisory committee and all involved that the sharing of these stories was beyond the scope of the pilot workshop at this time. Some Elders participating in this workshop expressed their interest in sharing their residential school experiences with the students. Therefore, future iterations of digital storytelling workshops may consider expanding their focus to include this request or to develop a full digital storytelling workshop dedicated specifically to the sharing and capturing of the Elders' experiences with residential schools. Digital storytelling was noted by some participants to be an appropriate medium through which Elders might share their experiences for future generations. 
At the Nak'al Bun Elementary School, the students regularly take culture classes that include the teaching of the Dakelh language and preserving cultural traditions and history. This workshop was an excellent opportunity to reinforce and build on these foundational learnings. Midway through the project, several Elders volunteered to be recorded while drumming and singing traditional songs, providing the students with yet another way of engaging with culture and integrating both spoken word and music into their digital stories. During this workshop, several Elders shared their oral stories in the Dakelh language with the students. This provided additional exposure to traditional language as spoken by the Elders. Students were challenged to understand the stories, and translations were provided by the Elder or by a multilingual family member who had accompanied the Elder. When recordings were provided in the Dakelh language, students were able to add English translations or to add subtitles in either language to their stories.

\section{Conclusion}

Introduction of an intergenerational digital storytelling workshop linking First Nations Elders and youth was positively received by all persons involved, including the students, Elders, community members, and members of the various communities and academic agencies involved. Developing and fostering intergenerational relationships through a digital storytelling workshop, where Elders and youth share cultural and experiential stories, are critical to preserving Elders' wisdom and knowledge for future generations. "It is never too late to sit and talk with the Elders. Our youth will learn so much" (Community showcase attendee).The introduction of digital software supported an opportunity for mutual sharing and learning between the generations as the Elders shared stories while the students shared their knowledge and expertise in using the software to work together to co-create the digital stories. The project title "Lha'hutit'en", meaning "we work together, we help one another", was originally given to this project by a Nak'azdli Elder in recognition of the authentic partnerships fostered through this work among the community partners led by the director of the Nak'azdli Health Centre and academic partners. However, this title also embodies the lasting intergenerational relationships fostered between the Elders and youth where they worked together to create digital stories to preserve their cultural knowledge and expertise for their community for future generations.

\section{References}

Archibald, J. A. (2008). Indigenous storywork: Educating the heart, mind, body, and spirit. Vancouver, BC: UBC press.

Bombay, A., Matheson, K., \& Anisman, H. (2009). Intergenerational trauma: Convergence of multiple processes among
First Nations peoples in Canada. International Journal of Aboriginal Health, 5(3), 6-47.

Burgess, J. (2006). Hearing ordinary voices: Cultural studies, vernacular creativity and digital storytelling. Continuum: Journal of Media and Cultural Studies, 20(2), 201-214.

Christensen, J. (2012). Telling stories: Exploring research storytelling as a meaningful approach to knowledge mobilization with Indigenous research collaborators and diverse audiences in community-based participatory research. The Canadian Geographer, 56(2), 231-242.

Cueva, M., Kuhnley, R., Revels, L., Schoenberg, N. E., \& Dignan, M. (2015). Digital storytelling: A tool for health promotion and cancer awareness in rural Alaskan communities. International Journal of Circumpolar Health 74(1), 1-6.

Cunsolo Willox, A., Harper, S. L., Edge, V. L., "My Word": Storytelling and Digital Media Lab, \& Rigolet Inuit Community Government. (2013). Storytelling in a digital age: Digital storytelling as an emerging narrative method for preserving and promoting Indigenous oral wisdom. Qualitative Research, 13(2), 127-147.

First Nations Information Governance Centre. (2014). Ownership, control, access and possession (OCAP $\left.{ }^{\circledR} \mathrm{TM}\right)$ : The path to First Nations information governance. Ottawa: The First Nations Information Governance Centre. Retrieved 15 November 2017 from http:/ / fnigc.ca/sites/default/files/ docs/ocap_path_to_fn_information_governance_en_ final.pdf

Fletcher, S., \& Mullett, J. (2016). Digital stories as a tool for health promotion and youth engagement. Canadian Journal of Public Health, 107(2), e183-e187.

Hausknecht, S. N. (2018). Connecting, sharing and reshaping life stories: Experiences, benefits, and challenges of older adults in a digital storytelling course (Doctoral dissertation). Vancouver, BC: Simon Fraser University.

Hausknecht, S., Vanchu-Orosco, M., \& Kaufman, D. (2016). New ways to tell my story: Evaluation of a digital storytelling workshop for older adults. In Proceedings of the 8th International Conference on Computer Supported Education (pp. 231-239). Rome: SCITEPRESS-Science and Technology Publications, Lda.

Hausknecht, S., Vanchu-Orosco, M., \& Kaufman, D. (2017) Sharing life stories: Design and evaluation of a digital storytelling workshop for older adults. In G. Costagliola, J. Uhomoibhi, S. Zvacek, \& B. McLaren, B. (Eds), Computers supported education. CSEDU 2016. Communications in computer and information science (p. 739). Cham, Switzerland: Springer.

Hausknecht, S., Vanchu-Orosco, M., \& Kaufman, D. (2018). Digitizing the wisdom of our Elders: Connectedness through digital storytelling. Ageing $\mathcal{E}$ Society, 1-21. https:/ / doi. org/10.1017/S0144686X18000739

Klaebe, H. G., Foth, M., Burgess, J. E., \& Bilandzic, M. (2007). Digital storytelling and history lines: Community engagement in a master-planned development. In Proceedings 
of the 13th International Conference on Virtual Systems and Multimedia: Exchange and Experience in Space and Place, VSMM 2007. Brisbane, Queensland, Australia: Australasian Cooperative Research Centre for Interaction Design Pty, Limited,

Lafontaine, C., \& Sawchuk, K. (2018, July). Promising practices in collaborative digital literacy and digital media-making with older adults. In International conference on human aspects of IT for the aged population (pp. 492-504). Cham, Switzerland: Springer. https:/ / doi.org/10.1007/978-3319-92034-4_37

Lambert, J. (2006). Digital storytelling: Capturing lives, creating community. Berkeley, CA: Digital Diner Press.

Livingstone, S., \& Bovill, M. (2013). Children and their changing media environment: A European comparative study. Routledge as cited in H. Ouellet, M. Romero, \& K. Sawchuk (2017). Promoting intergenerational participation through game creation activities. In Game-based learning across the lifespan (pp. 79-89). Cham, Switzerland: Springer. https://doi. org/10.1007/978-3-319-41797-4_6

Miles, M., \& Huberman, M. (1994). Qualitative data analysis: An expanded sourcebook. Thousand Oaks, CA: Sage Publications.

Nak'al Bun Elementary School. (n.d.). About us. Retrieved 15 March 2018 from https://www.nakalbun.ca/aboutus.html

Nak'azdli Whut'en. (n.d.). Nak'azdli Whut'en: We challenge the future. Retrieved 15 March 2018 from https:/ / nakazdli. wordpress.com
Neergaard, M. A., Olesen, F., Andersen, R. S., \& Sondergaard, J. (2009). Qualitative description-the poor cousin of health research? BMC Medical Research Methodology, $9(1), 52$.

Northern Health, Nak'azdli Whut'en, \& Tl'azt'en First Nation. (2015). Nak'azdli 'ink'ez Tl'azt'en Wheni noh bulh yas'ulhtuk. Nak'azdli and Tl'azten: We are telling you. V. Author

O'Donnell, M. Wendt, and the National Association of Friendship Centres. (2017) Aboriginal seniors in population centres in Canada. Ottawa: Statistics Canada. Retrieved 15 March 2018 from https://www150.statcan.gc.ca/n1/ pub/89-653-x/89-653-x2017013-eng.htm

Ouellet, H., Romero, M., \& Sawchuk, K. (2017). Promoting intergenerational participation through game creation activities. In Game-based learning across the lifespan (pp. 79-89). Cham, Switzerland: Springer. https:// doi.org/10.1007/978-3-319-41797-4_6

Province of British Columbia. (2018). BC's new curriculum. Retrieved 4 January 2018 from https://curriculum.gov. bc.ca/sites / curriculum.gov.bc.ca / files / curriculum / adst/en_adst_k-9.pdf

Sawchuk, K. (2016). Introduction. Aging, communication and media technologies. Romanian Journal of Communication and Public Relations, 18(1), 7-10.

Tonkin, R., Freeman, S., Martin, J., Ward, V., \& Skinner, K. (2018). First Nations Elders' perspectives of engagement in community programs in Nak'azdli Whut'en, British Columbia, Canada. Canadian Journal of Public Health, 109(5-6), 717-725. 